\title{
SEASONAL CHANGES OF MACRO- AND MICROELEMENTS CONTENT IN SOILS OF GREEN TEA FARMING FROM RIZE (TURKEY)
}

\author{
Fatih İslamoğlu*, Özlem Buçan, Oktay Torul, Naciye Erdoğan \\ Department of Chemistry, RecepTayyip Erdogan University, 53100 Rize, Turkey \\ *e-mail:fatih.islamoglu@erdogan.edu.tr
}

\begin{abstract}
During 2014 year, 60 soil samples at the point of 30 soil samples in the spring and 30 soil samples in autumn were taken from the localities of Findikl $141^{\circ} 16^{\prime} 14.40^{\prime \prime} \mathrm{N}-41^{\circ} 08^{\prime} 24.13$ ”E), Pazar $\left(41^{\circ} 10^{\prime} 50.06^{\prime} \mathrm{N}-40^{\circ} 53^{\prime} 11.35^{\prime \prime} \mathrm{E}\right)$ and Sabuncular (41 04 '20.79' $\left.\mathrm{N}-40^{\circ} 43^{\prime} 13.51^{\prime \prime} \mathrm{E}\right)$ from Rize (Turkey), where green tea has been cultivated. The value of $\mathrm{pH}$, content of the organic matter, and amount of macro- and microelements amount were determined in sampled soils and the seasonal changes were investigated. According to the obtained results, it was established that, in general, the values of $\mathrm{pH}$, as well as the content of macro- and microelements in spring were higher than those recorded in autumn.
\end{abstract}

Keywords: soil samples, macroelements, microelements, $\mathrm{pH}$, organic matter.

Received: August 2016/ Revised final: October 2016/ Accepted: November 2016

\section{Introduction}

Soil is a natural organic structure, having both mineral and organic constituents, in addition to biological, physical, and chemical features. Hence, the soil properties cannot be a simple reflexion on the connected features of all soil components. Chemical elements in soil refer to as trace elements (TEs), because of their occurrence at concentrations less than $100 \mathrm{mg} \cdot \mathrm{kg}^{-1}$. Many of these elements are present at concentrations much lower than this value. The most of trace elements, which have environmental and human/animal health significance, are metals, such as: cadmium, chromium, cobalt, copper, gold, lead, manganese, mercury, molybdenum, nickel, palladium, platinum, rhodium, silver, thallium, tin, vanadium and zinc. Other significant TEs belong to the metalloid (e.g. boron, arsenic, and antimony), non-metal (e.g. selenium), actinoid (e.g. uranium) and halogen (e.g. iodine and fluorine) groups of elements [1]. The combination of soils is exceedingly different and, although, controlled by many different agents, the climatic conditions and the parent material predominate most ordinarily. Soil is a combination of solid (mineral and organic section), liquid, and gaseous phases. Furthermore, not only the chemical combination of soil, but also its mineral structure and the expression of distribution are significant factors, influencing soil properties.

Trace elements have also been termed "toxic metals", "trace metals" or "heavy metals", although none of these terms is entirely satisfactory from a chemical viewpoint. "Heavy metals" is the most popularly used and widely recognized term for a large group of elements with a density greater than $6 \mathrm{~g} \cdot \mathrm{cm}^{-1}$, but all TEs are metals [2]. Similarly, the term "toxic metals" is not suitable as TEs become toxic to living organisms only when they are at excess levels. For this reason, TEs are also frequently referred as potentially toxic trace elements (PTEs); this term is more comprehensive and appropriate than toxic or heavy metals. The term "trace element" is utilitarian as it clasps metals, metalloids, nonmetals and other elements in the soil-plant-animal system, but it is somewhat indefinite, because it can incorporate any element notwithstanding of its function.

Seven elements, such as: chlorine, manganese, iron, zinc, boron, copper and molybdenum, are important nutrients required in trace amounts for plant growth, as well as human and animal health, although chlorine and iron within soils and plants are not TEs, because their average concentration is generally greater than $100 \mathrm{mg} \cdot \mathrm{kg}^{-1}$. These elements are necessary for maintaining the life processes in plants and/or animals, including humans and, therefore, they are important micronutrients [2]. Cobalt, chromium, fluorine, iodine, nickel and selenium found in plants are not important nutrients as such, but animals have developed a dependency on these elements for use in their metabolic procedures. Cobalt is also required by microorganisms for atmospheric-nitrogen obsession and by ruminants for their rumen bacteria. Although the biological role of these elements is not fully understood, they are considered as important beneficial TEs [3]. There is little evidence to suggest that arsenic, cadmium, lead and mercury play a nutritive role in higher plants and animals [4].

The aim of this work was (i) determination of the $\mathrm{pH}$ value, organic matter content, amount of the macro- and microelements and (ii) evaluation of seasonal changes of these parameters in soils sampled from Rize (Turkey), where the green tea has been cultivated.

\section{Materials and methods Materials}

In this study, 60 soil samples at the point of 30 soil samples in spring and 30 soil samples in autumn were taken from the localities of Findikl1, Pazar and Sabuncular, where the green tea has been cultivated in Rize (Turkey)

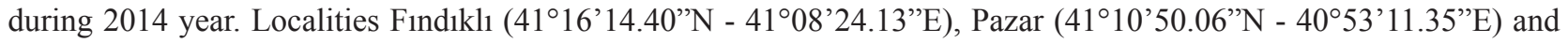
Sabuncular $\left(41^{\circ} 04^{\prime} 20.79^{\prime} \mathrm{N}-40^{\circ} 43^{\prime} 13.51^{\prime} \mathrm{E}\right)$ are given by the coordinates in Figure 1. 


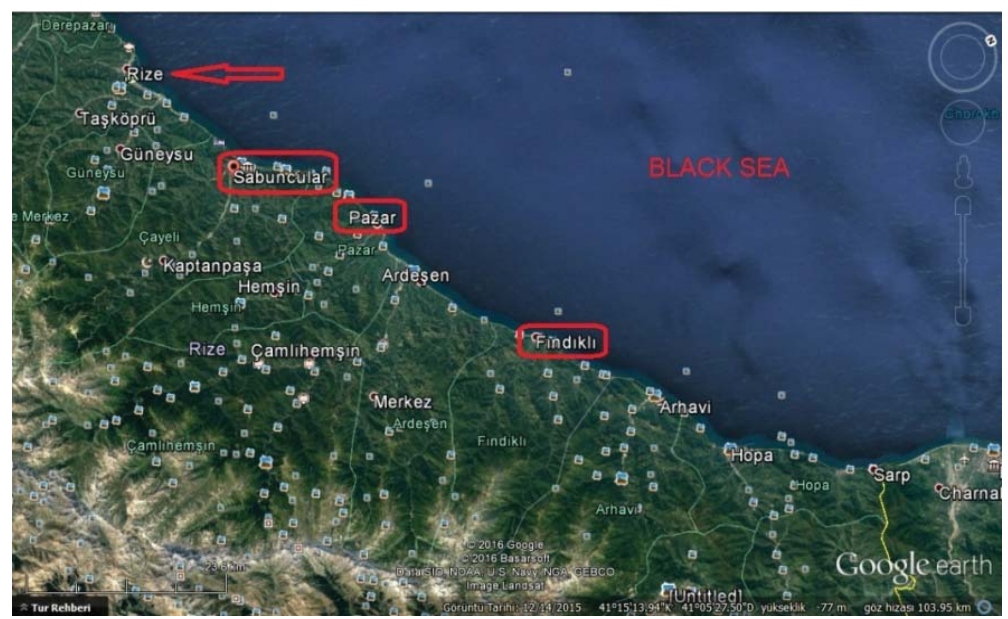

Figure 1. Studied regions on the map.

\section{Preparation of soil samples}

Four basic stages, which help to determine the representativeness and reliability of approach, were defined as follows: Stage 1 - pre-sampling assessment and plan; Stage 2 - soil sampling; Stage 3 - soil pre-analysis treatment (which includes soil preparation and storage); and Stage 4 - soil analysis [1]. The samples were collected from the three different sampling points (Sabuncular, Pazar and Findıklı in Rize (Turkey)) during two different seasons (April (I) and November (II)). The most soil samples are collected using a specific corer or auger. These primary samples are subsequently either combined (composite/aggregated) or kept and analysed separately (Figure 2).

The logistics, costs, obtained information and interpretation that is likely to be gained from both of these two approaches is very different [1]. The number and relative position of the sampling points depend on the scope of sampling and, thus, on the particular sampling strategy chosen, which can be selected on a statistical basis [1]. When these primary samples are mixed together, a composite/aggregate sample is obtained. A sample ready for the laboratory can be obtained either directly from the primary sample or from the composite sample [1].

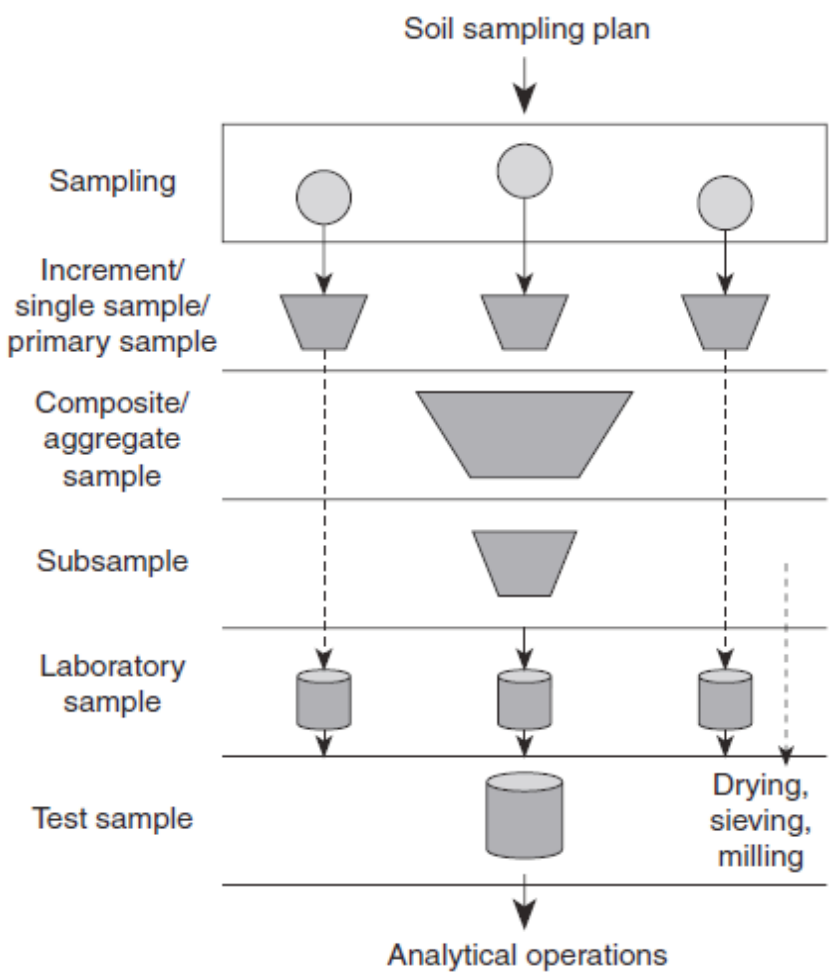

Figure 2. Sampling operations [5]. 


\section{Methods}

All chemicals used in this study were purchased from Merck and were of analytical grade. The value of $\mathrm{pH}$, organic matter content, amount of the macro- and microelements were determined in all soil samples. Each determination was repeated 3 times.

pH value

The $\mathrm{pH}$ measurement was carried out after $\mathrm{pH}$ meter electrodes were plunged in the suspension of soil, according to the recommendations presented in [6-7].

Organic matter content

Organic matter in soil sample was digested by oxidation with acid-dichromate solution. The excess of dichromate was titrated with $\mathrm{KMnO}_{4}$ solution, using ferrous(II) sulphate solution as indicator [8].

Nitrogen content

The soil sample was subjected to digestion with concentrated $\mathrm{H}_{2} \mathrm{SO}_{4}$ and solubilisation mixture $\left(\mathrm{Na}_{2} \mathrm{SO}_{4}\right.$ or $\mathrm{K}_{2} \mathrm{SO}_{4}+\mathrm{CuSO}_{4} \cdot 5 \mathrm{H}_{2} \mathrm{O}+\mathrm{FeSO}_{4} \cdot 7 \mathrm{H}_{2} \mathrm{O}$ ). The soil extract was titrated with boric acid in micro-Kjeldahl apparatus and the nitrogen content was calculated by the corresponding formula [8].

Phosphorus content

Phosphorus content in soil samples was determined after digestion by extraction solution $\left(\mathrm{NH}_{4} \mathrm{~F}+0.5 \mathrm{~N} \mathrm{HCl}\right)$. Phosphorus content was determined in filtrate solution after adding ammonium molybdate in the presence of aqueous tin(II) chloride, at $660 \mathrm{~nm}$ wave length [8].

Potassium content device [8].

Potassium content was determined, after digestion of soil sample by ammonium acetate, in flame photometer

Calcium content

Solution after digestion by ammonium acetate was titrated with $0.01 \mathrm{~N}$ EDTA in the presence of ammonium purpurate in alkaline medium. The calcium content was calculated by the corresponding formula [8].

Calcium + magnesium content

Solution after digestion by ammonium acetate was titrated with $0.01 \mathrm{~N}$ EDTA in the presence of eriochrom black - T indicator. The magnesium content was calculated by the corresponding formula [8].

Iron, manganese, zinc and copper content

The soil sample was subjected to digestion with DTPA solution (diethylene triaminepentaacetic acid $+\mathrm{CaCl}_{2}$ + triethanolamine). The content of iron, manganese, zinc and copper was determined in soil extracts by using atomic absorption spectrometry (AAS) at $248.3 \mathrm{~nm}, 279.5 \mathrm{~nm}, 213.9 \mathrm{~nm}$ and $324.7 \mathrm{~nm}$ respectively.

Replaceable aluminium

Aluminium was determined by atomic absorption spectrometry (AAS) at $309.3 \mathrm{~nm}$ wavelength, after soil treatment with a solution of potassium chloride.

Devices

For this study the following devices were used: $\mathrm{pH}$ meter (Thermo Orion, X01162), spectrophotometer (Shimadzu, UV-1800), nitrogen distillation apparatus (Gerhardt, 7145110018), flame photometer (BWB XP flame photometer), age incinerator (Gerhardt, 7043130020), shaker (Selecta, 480151), atomic absorption spectrometry (GBC, Avanta T) and precision balances (Precisa, XB620M).

\section{Results and discussion}

In this study, soil samples were taken from the region of Sabuncular, Pazar and Findıklı in Rize (Turkey) during April and November, 2014. A total of 30 soil samples was obtained from 10 different manufacturers in each region. Twelve separate analyses of each of these soil samples were performed (a total of 360).

pH value

The $\mathrm{pH}$ value of the tea agricultural land in Rize ranged from mild to exceptionally acidic. The $\mathrm{pH}$ value ranged from 3.42 to 6.12 . It was determined that the $\mathrm{pH}$ value in the most cases was below of 4.50 . In $86.6 \%$ of the soil samples the value of $\mathrm{pH}$ was recorded between 4.50 and 6.00 , which is considered ideal for tea growing. In $76.6 \%$ of samples the exceptionally acidic $\mathrm{pH}$ value was registered, while $23.4 \%$ of samples had the ideal value of $\mathrm{pH}$. The results for each zone and season are given in the Tables 1-3.

According to the results presented in Tables 1-3, the higher values of $\mathrm{pH}$ were observed in soil sampled during April. Organic fertilizers used in spring are considered as one of the reasons. It has led to the rise of $\mathrm{pH}$ due to the properly processing of the soil containing the applied organic fertilizer, by rainfall. In the autumn, the effect of organic fertilizer is reduced. Secondly, the drop in the $\mathrm{pH}$ value during November is caused by pollution through rainwater contaminated with organic fertilizer. It has led to the emergence of a significant negative effect that can be considered in the literature of the uncontrolled use of agricultural chemicals in our country and uncontrolled of manufacturers in this topic. Our tea producers have applied ammonium sulphate $\left(\left(\mathrm{NH}_{4}\right)_{2} \mathrm{SO}_{4}\right)$ fertilizer in excessive quantity and onesidedly despite all warnings. Consequently, more than $95 \%$ of our tea soils in 30 years have gained an excessive level of acidity and the $\mathrm{pH}$ of soil has dropped below the lower limit of $\mathrm{pH}(4.5)$. As a result, it appears to be compatible with the average values of $\mathrm{pH}$ obtained in April for tea cultivation, considering $\mathrm{pH}$ value of $4.5-6.0$. The $\mathrm{pH}$ variation in soils of Sabuncular region is presented in Figure 3. 
$\frac{\sqrt{\frac{1}{3}}}{\frac{0}{3}}$

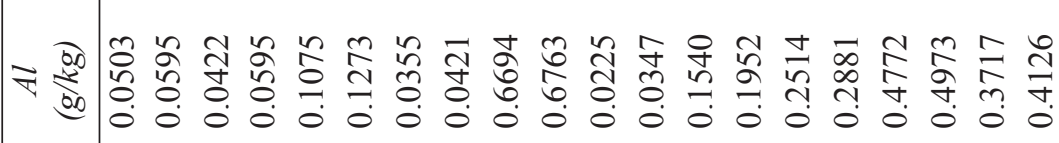

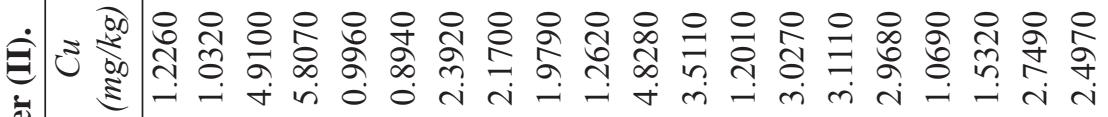

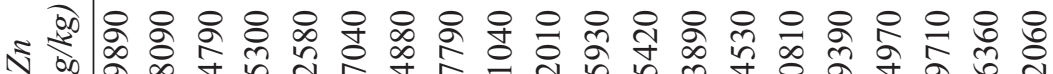

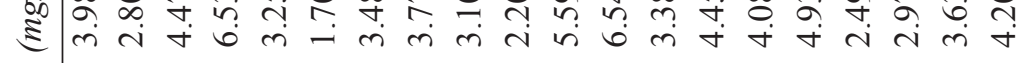

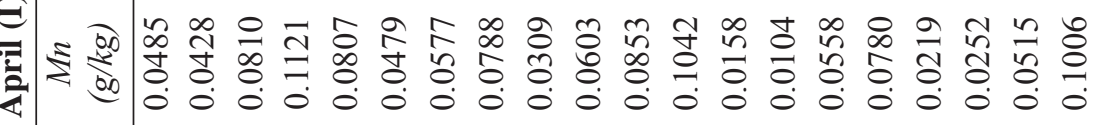

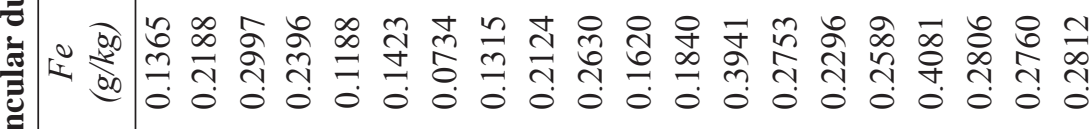
w

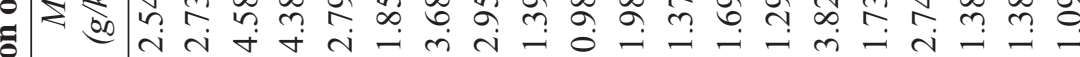

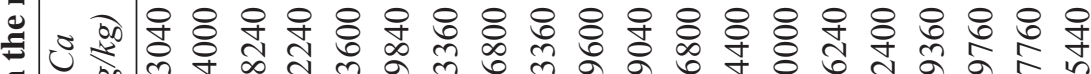

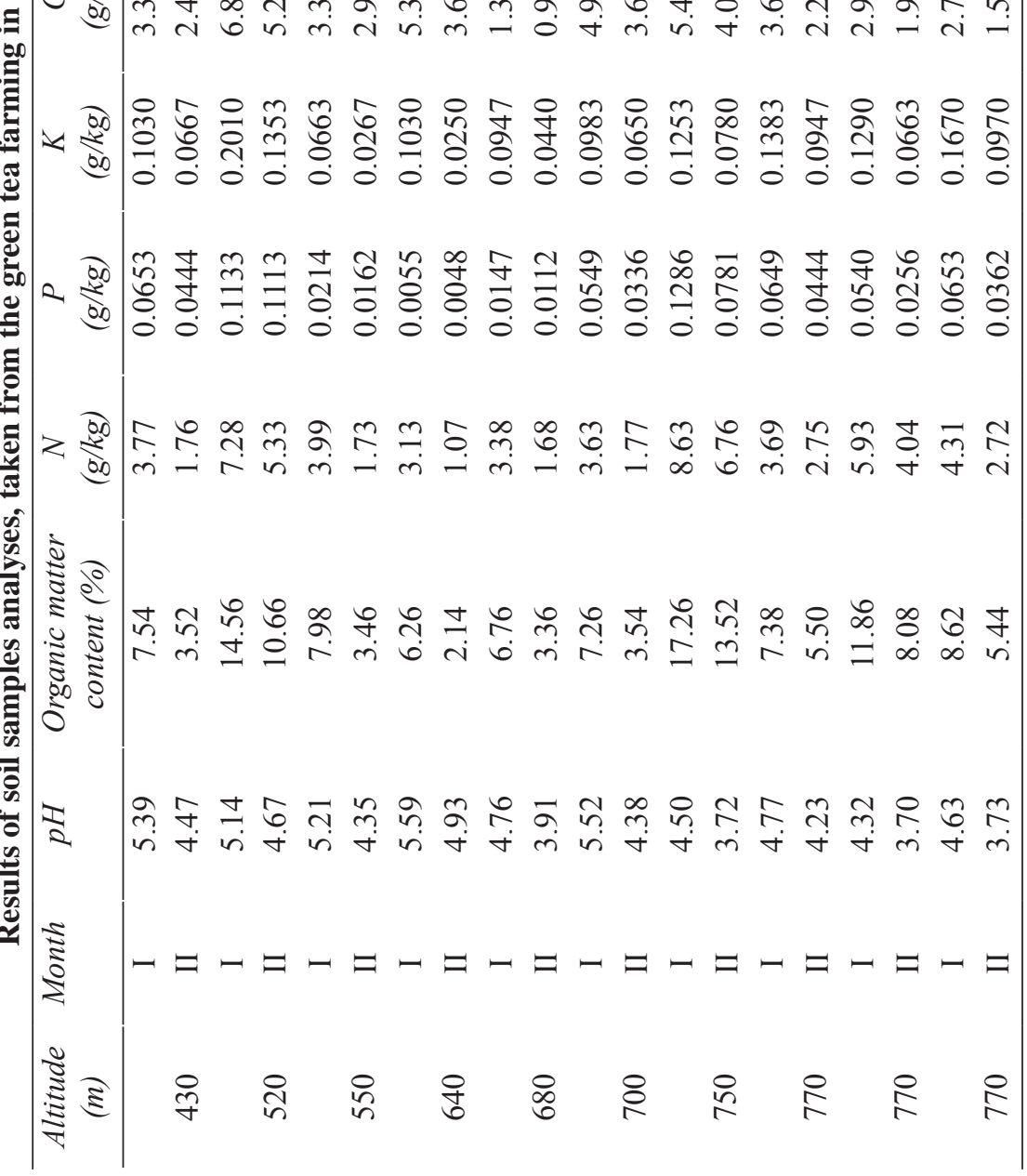




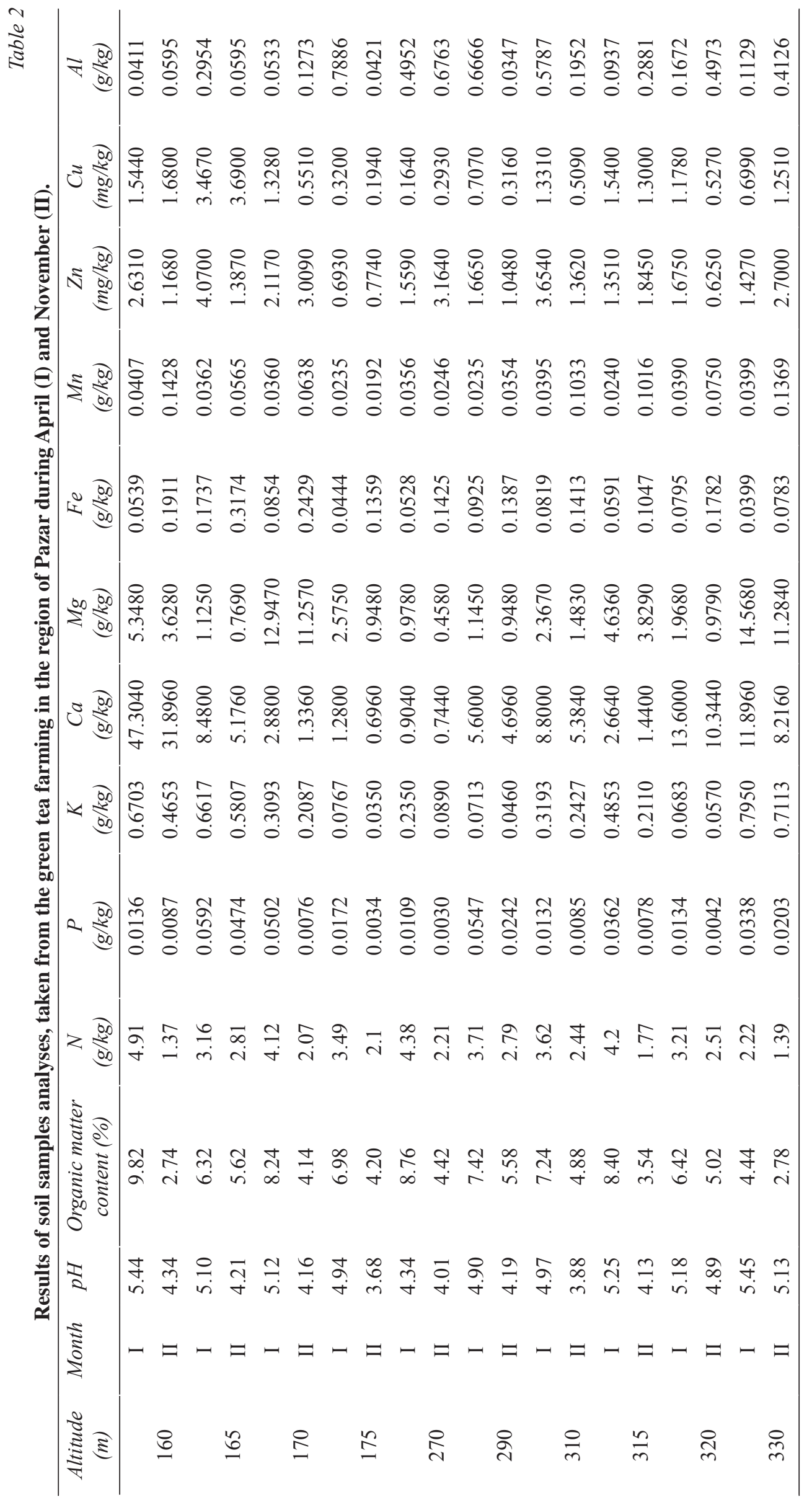




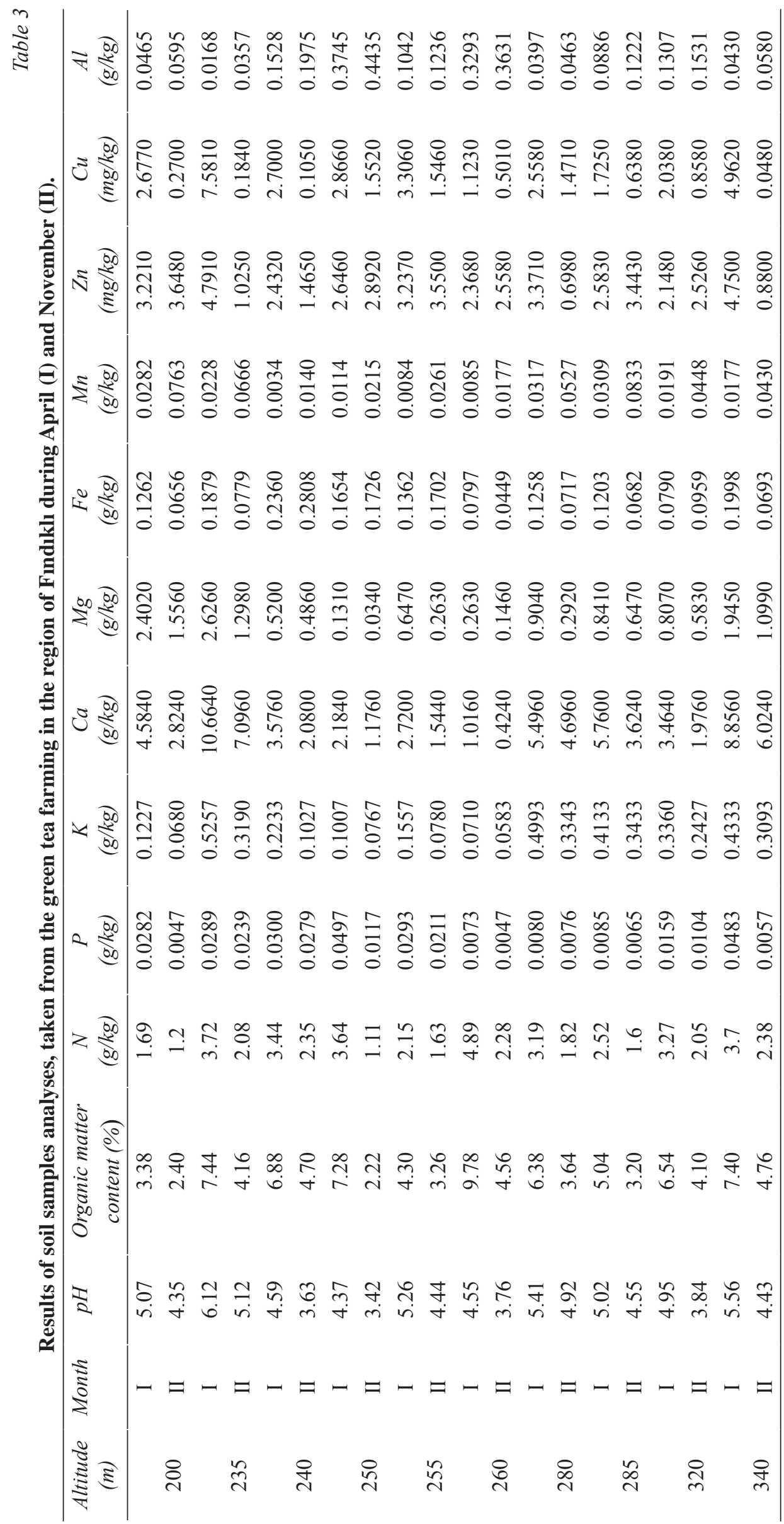




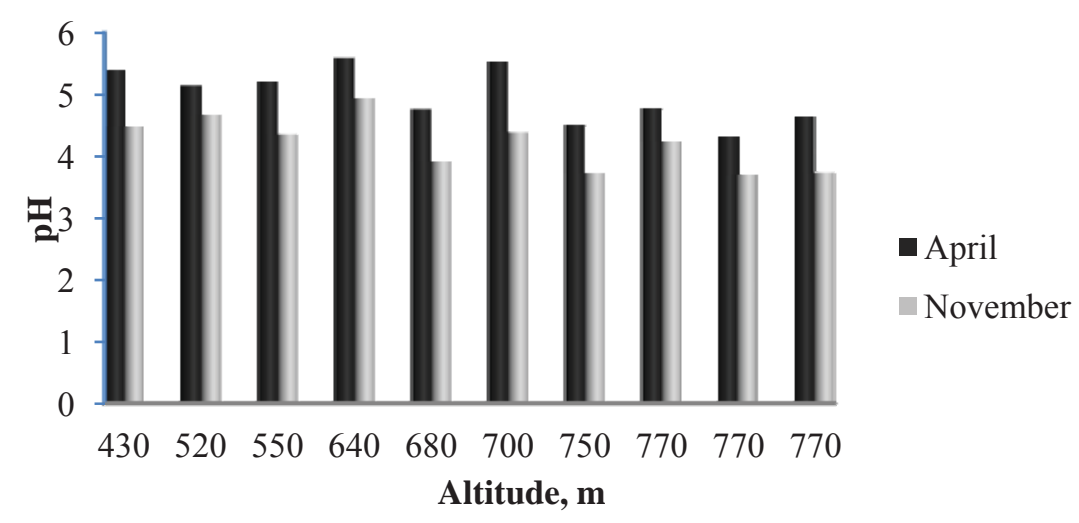

Figure 3.

Variation of $\mathrm{pH}$ value in soil sampled from Sabuncular region.

\section{Organic matter content}

In $13.3 \%$ of soil sampled during April the organic matter content was at high level, while in $86.7 \%$ of samples was at very high level. During November there were registered the following results: in $16.7 \%$ of samples the organic matter content was at medium level, in $73.3 \%$ - at high level and in $10.0 \%$ - at very high level. Similar results were identified in another study in Rize [9]. The values of organic matter content vary widely in soil of tea garden during April and November. This is explained by the fact that each month is characterized by abundant rainfall and low temperatures. Dynamics of organic matter content registered in Sabuncular region is shown in Figure 4.

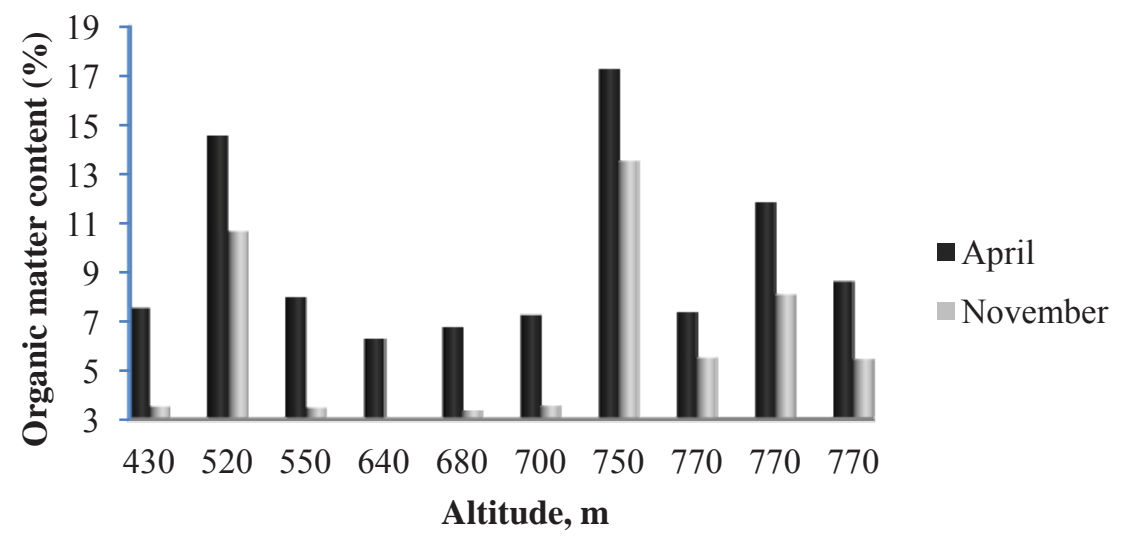

Figure 4.

Variation of organic matter content in soil sampled from Sabuncular region.

\section{Nitrogen content}

The nitrogen content in soil samples ranged from $1.1 \mathrm{~g} / \mathrm{kg}$ to $8.6 \mathrm{~g} / \mathrm{kg}$. In $10 \%$ of soil sampled during April the nitrogen content was at high level, while in $90 \%$ of samples was at very high level. During November there were registered the following results: in $16.7 \%$ of samples the nitrogen content was at medium level, in $56.7 \%$ - at high level and in $10.0 \%$ - at very high level. The nitrogen ratio was similar to organic matter content. Thus, we can conclude that nitrogen is originated from organic matter in the soil.

A dynamics of nitrogen content in a study conducted between 1978 - 1982 years for 1667 soil samples at same region was reported [10]. Also, Müftüoğlu et al. determined the nitrogen content of the tea garden soils, classifying them as group of low, medium, high and very high [11]. There were identified the following groups: $3.78 \%$ low, $16.09 \%$ medium, $40.59 \%$ high and $39.53 \%$ very high in a study of soil samples [12]. It appears that these values are compatible with our results. The variation of nitrogen content recorded in Sabuncular region is presented in Figure 5.

\section{Phosphorus content}

The phosphorus content in soil sampled in April and November ranged from $0.0030 \mathrm{~g} / \mathrm{kg}$ to $0.1286 \mathrm{~g} / \mathrm{kg}$. Comparing the obtained results with results performed in another study in the same region, which include research of 1815 soil samples [10], the increasing of phosphorus content in the soil was observed.

The phosphorus amount in samples taken in November was lower than the phosphorus content in samples collected in April. The reason is a reduction of $\mathrm{pH}$ value in soils. In soil phosphorus reacts with $\mathrm{Al}, \mathrm{Fe}, \mathrm{Mn}$ and insoluble hydrated oxides of these elements under acidic conditions, with $\mathrm{Ca}$ and $\mathrm{Mg}$ - in alkaline conditions. Phosphorus is a nutrient, being the most affected by the soil reaction. From the soil, plants often use the $\mathrm{HPO}_{4}^{-2}$ and $\mathrm{H}_{2} \mathrm{PO}_{4}{ }^{-}$form of phosphorus. Plants utilize phosphorus in the form of $\mathrm{H}_{2} \mathrm{PO}_{4}^{-}$when $\mathrm{pH}$ value is lower than 6.71 and in the form of $\mathrm{HPO}_{4}^{-2}$ 
when $\mathrm{pH}$ value is higher than 6.71 . The solubility of the phosphate increases when the amount of alkali metal salts in the soil augments, depending on $\mathrm{pH}$ value. As a result, the plant benefits the phosphorus at $\mathrm{pH}$ values in limits of 5-7. Phosphorus content variation identified in Sabuncular region is shown in Figure 6.

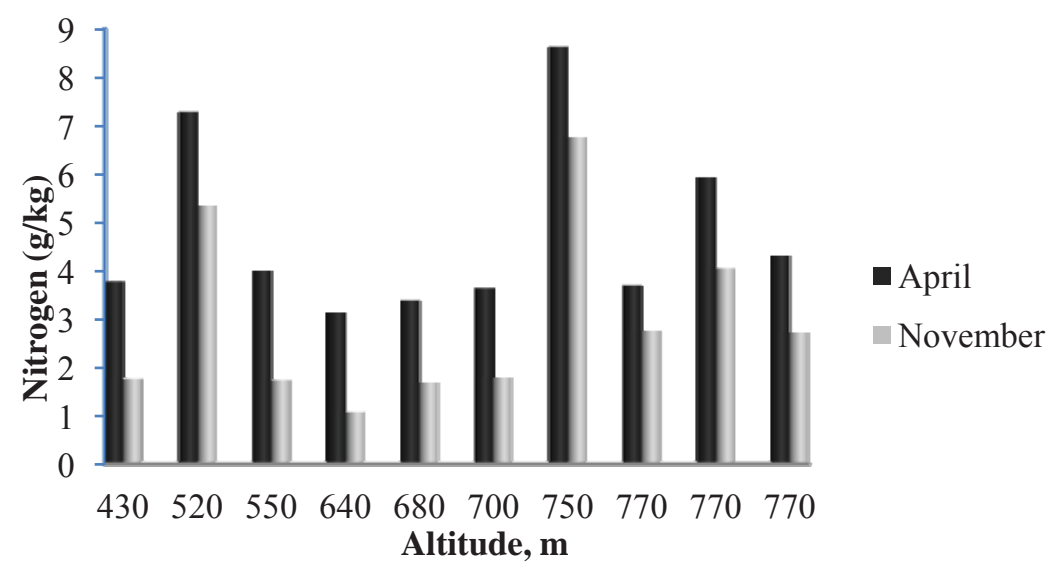

\author{
Figure 5. \\ Variation of nitrogen \\ content in soil samples from \\ Sabuncular region.
}

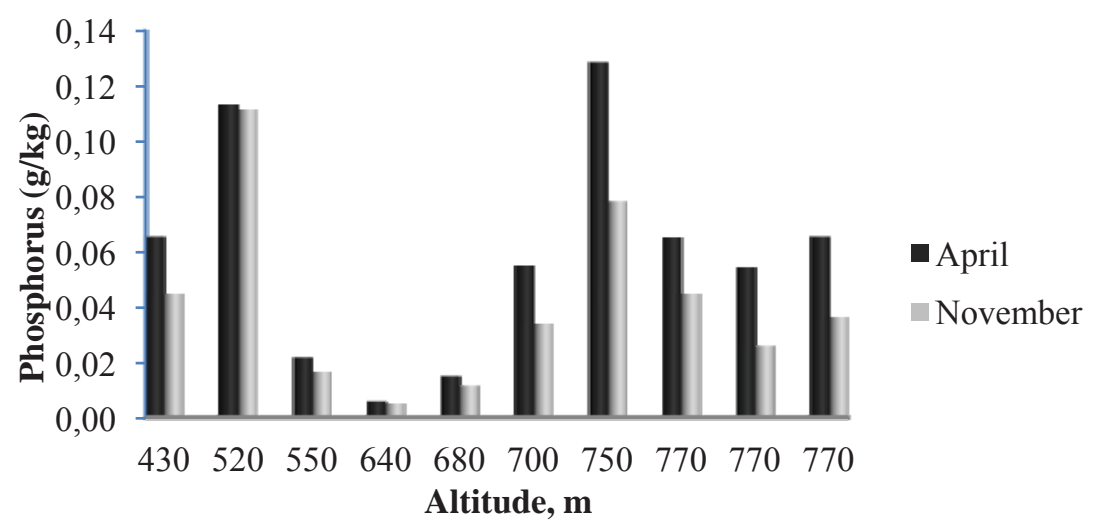

Figure 6.

Variation of phosphorus content in soil samples from Sabuncular region.

\title{
Potassium content
}

In soil sampled during April in $46.7 \%$ of samples the potassium content was at low level, while in $26.7 \%$ of samples was at sufficient level, and in $26.6 \%$ - at high level. During November there were registered the following results: in $16.7 \%$ of samples the potassium amount was at very low level, in $46.7 \%$ - at low level, in $26.6 \%$ - at sufficient level and in $10.0 \%$ - at very high level. By comparing our results with the results of another study in the same region, which include research of 1678 soil samples [13], it is observed an increasing the potassium amount in the soil.

Potassium content in the samples taken in November was lower than the potassium levels in April. It can be stated that decreasing the $\mathrm{pH}$ value, increasing the precipitation quantity and freeze-thaw phenomena in the soil are the reasons for this fact. It is not exactly determined that increasing the potassium level in the soil depends on the $\mathrm{pH}$ value. It is accepted as a general rule that the potassium level increases in the conditions of high $\mathrm{pH}$ [14]. Potassium amount dynamics in soils sampled from Pazar region is presented in Figure 7.

\section{Calcium content}

The calcium content in soil sampled in April and November ranged from $0.424 \mathrm{~g} / \mathrm{kg}$ to $47.304 \mathrm{~g} / \mathrm{kg}$. Calcium content values in soil samples were higher than the normal values during both seasons. In $36.7 \%$ of the samples taken in the spring and in $40.0 \%$ of the samples taken in the autumn the calcium content had the desirable values. The dynamics of calcium content in soils sampled in Pazar region is shown in Figure 8.

\section{Magnesium content}

In soil sampled during April in 3.3\% of samples the magnesium content was at sufficient level, while in $33.4 \%$ of samples was at high level, in $60.0 \%$ - at very high level. During November there were registered the following results: in $10.0 \%$ of samples the magnesium amount was at sufficient level, in $50.0 \%$ - at high level, in $33.3 \%$ - at very high level. The values of magnesium content in the soil samples were higher than the normal values during both seasons. In $3.3 \%$ of the samples taken in the spring and in $10.0 \%$ of the samples taken in the autumn the magnesium content had the desirable values. A dynamics of magnesium content in soils sampled in Pazar region is shown in Figure 9. 


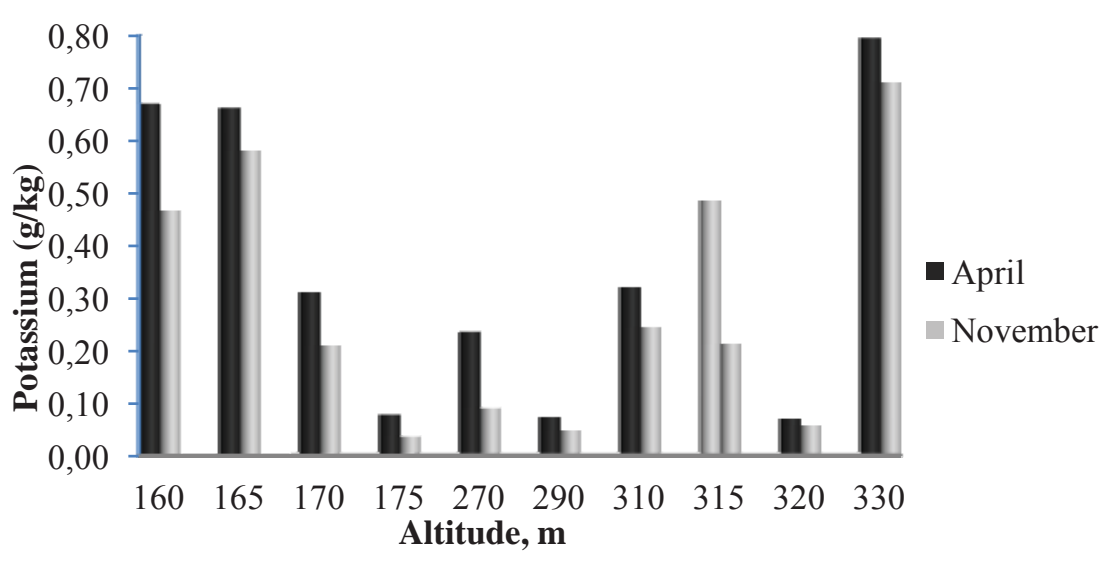

Figure 7.

Variation of potassium content in soil samples from Pazar region.
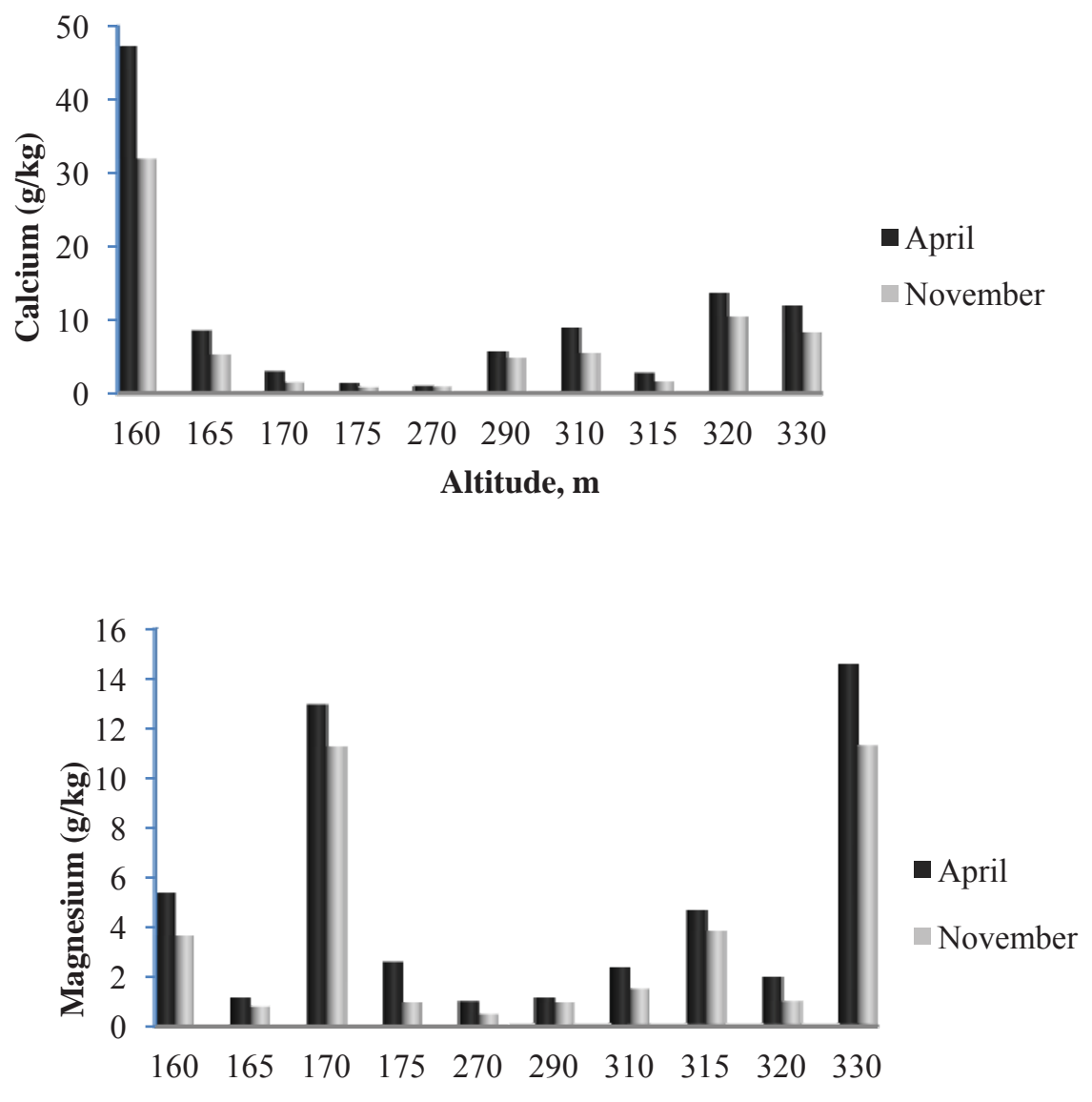

Figure 9.

Variation of magnesium content in soil samples from Pazar region.

Altitude, m

\section{Iron content}

The iron content of samples taken in April was at medium level in 6.7\% of samples, at a high level in $40.0 \%$ of samples and at a very high level in $53.3 \%$ of samples. In November the iron amount was registered at medium level in $3.3 \%$ of samples, at a high level in $26.7 \%$ of samples and at a very high level in $70.0 \%$ of samples. In $40.0 \%$ of samples taken in the spring and in $26.7 \%$ of samples collected in the autumn the iron content had the desirable values. The reason is the decline of $\mathrm{pH}$ value between the two seasons. The higher values of $\mathrm{pH}$ in the spring cause the iron content decreasing, whereas the fall in $\mathrm{pH}$ values in autumn causes the iron content increasing above the normal values.

It was determined that the values of iron content ranged between $0.0036-0.0448 \mathrm{~g} / \mathrm{kg}$ in a study conducted in 8 gardens between the years of 1977-1978 in the same region [14]. Taking into account these data, it seems to be an increase in values of iron amount in our tea land. Toxic effects causing an excess of soluble iron in plants, which lack of useful iron content, contribute to excessive iron deficiency in some soils. The variation of iron content in soil sampled in Pazar region is presented in Figure 10. 


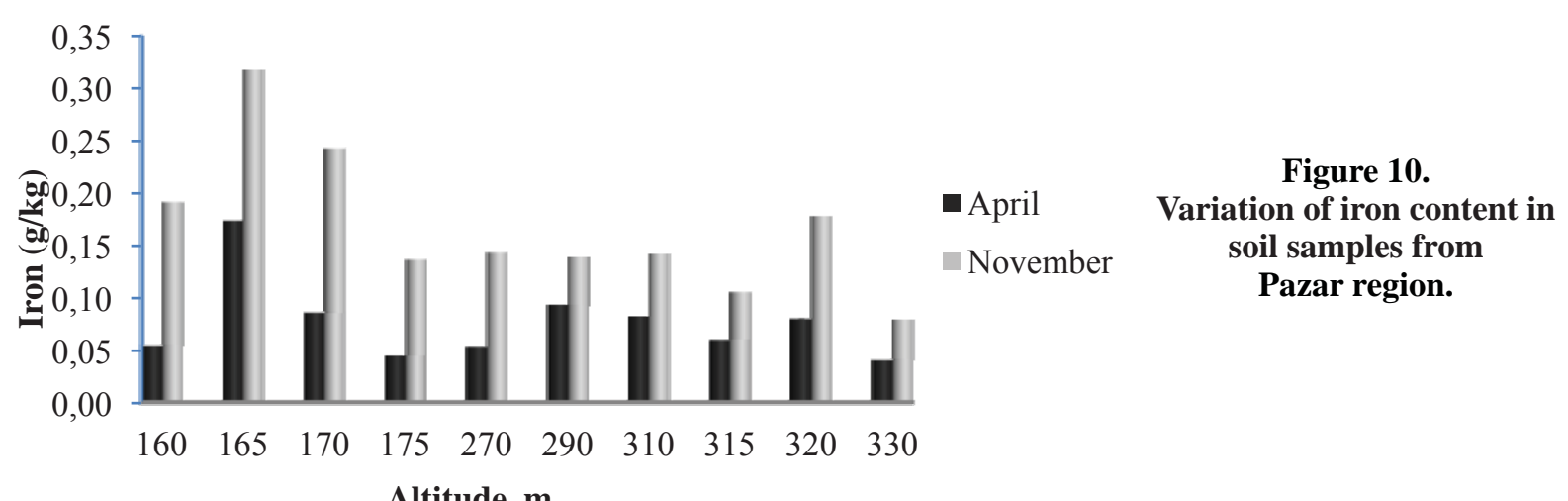

\section{Manganese content}

The manganese content in samples taken in April was at medium level in $76.7 \%$ of samples and at a very high level in $23.3 \%$ of sample. In November the manganese content in $36.7 \%$ of samples was at medium level, in $40.0 \%$ of samples - at high level and in $23.3 \%$ of samples - at very high level. In $23.0 \%$ of samples taken in the spring and in $40.0 \%$ of samples taken in the autumn the manganese amount had the desirable values. It is determined the manganese values ranged between $0.0019-0.0405 \mathrm{~g} / \mathrm{kg}$ in a study conducted in 8 gardens between the years of 1977-1978 in the same region [15]. As a result, an increase in the value of manganese content was observed in samples taken in November. The variation of the manganese amount in soil sampled in Findıkl region is shown in Figure 11.

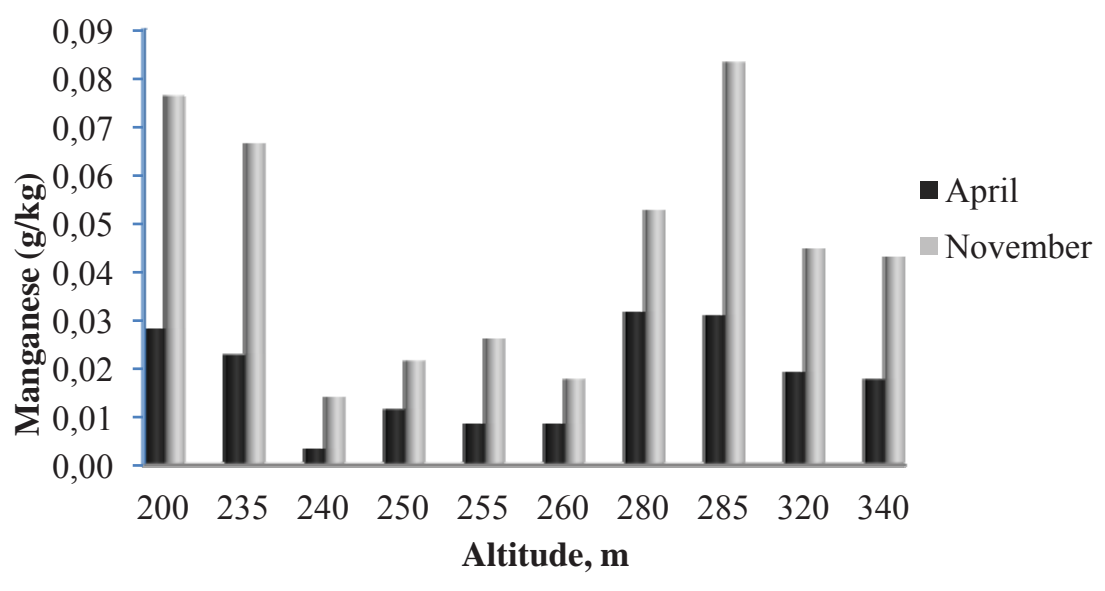

Figure 11.

Variation of manganese content in soil samples from Findıklı region.

\section{Zinc content}

The zinc content in samples taken in April was at medium level in $20.0 \%$ of samples and at a very high level in $80.0 \%$ of samples. In November the zinc amount was at medium level in $40.0 \%$ of samples and at a high level in $60.0 \%$ of samples. In $80.0 \%$ of samples taken in the spring and in $60.0 \%$ of samples taken in the autumn the zinc amount had the desirable values. The amount of zinc ranged between $0.12-4.05 \mathrm{mg} / \mathrm{kg}$ in a study conducted in 8 gardens between the years of 1977-1978 in the same region [15]. As a result, a decrease in the value of zinc content was observed in samples collected in November. The variation of zinc content in soil sampled in Fındıklı region is shown in Figure 12.

\section{Copper content}

The copper content in samples taken in April was in $16.7 \%$ of samples at medium level, in $80.0 \%$ - at a high level and in 3.3\% - at a very high level. In November the copper content was in $46.7 \%$ of samples at medium level and in $53.3 \%$ - at a high level. The copper content ranged between $0.06-5.93 \mathrm{mg} / \mathrm{kg}$ in a study conducted in 8 gardens between the years of 1977-1978 in the same region [15]. As a result, an increase in the value of the copper amount was observed in soil sampled during two seasons. Dynamics of the copper amount in soil sampled in Findıklı region is presented in Figure 13.

\section{Aluminium content}

The aluminium content in samples taken in April was at low level in $63.3 \%$ of samples and at medium level in $36.7 \%$. In $53.3 \%$ of samples it was at low level and in $46.7 \%$ at medium level during November. The variation of aluminium content in soil sampled in Findıklı region is shown in Figure 14. 

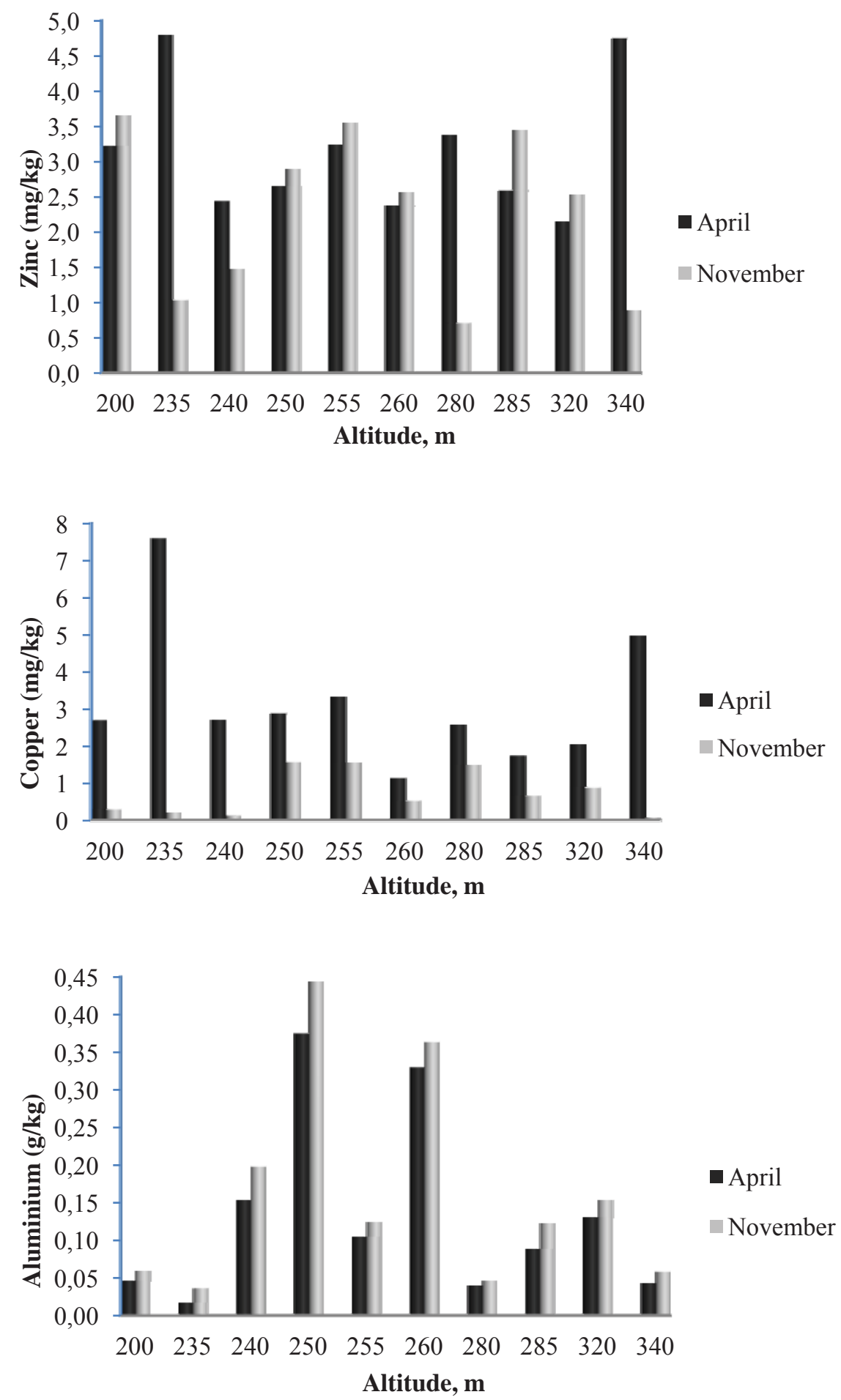

Figure 13.

Variation of copper content in soil samples from Findıklı region.
Figure 12.

Variation of zinc content in soil samples from Findıklı region. 


\section{References}

1. Hooda, P.S. Trace Elements in soils. John Wiley and Sons Ltd.: Chichester, 2010, pp. 53-56.

2. Bennett, W.F. Ed. Nutrient Deficiencies \& Toxicities in Crop Plants. APS Press: New York, 1993, pp. 28-32.

3. Johnston, A.E. Trace elements in soil: status and management in Essential Trace Elements for Plants. Animals and Humans NJF Seminar: Iceland, 2005, pp. 71-74.

4. Adriano, D.C. Trace elements in the terrestrial environment. Springer: New York, 1986, pp. 43-45.

5. De Zorzi, P.; Barbizzi, S.; Belli, M.; Ciceri, G.; Fajgelj, A.; Sansone, U.; Van Der Perk, M. Terminology in soil sampling. Pure and Applied Chemistry, 2005, 77, pp. 827-841.

6. Kalra, Y.P. Determination of $\mathrm{pH}$ of soils by different methods: Collaborative study. Journal of AOAC International, 1995, 78, pp. 310-321.

7. Noli, F.; Tsamos, P. Concentration of heavy metals and trace elements in soils, waters and vegetables and assessment of health risk in the vicinity of a lignite-fired power plant. Science of the Total Environment, 2016, 563, pp. 377-385.

8. Bremner, J.M.; Mulvaney, C.S. Methods of soil analysis. Part 2. Chemical and microbiological properties. Academic Press:USA, 1982, pp. 595-624.

9. Sarimehmet, M.; Müftüoğlu, N.M. Status of organic matter at tea agricultural soil in Eastern Black Sea region. Journal of Ege University Faculty of Agriculture, 1993, 30, pp. 49-56.

10. Sarimehmet, M.; Müftüoğlu, N.M. Status of nitrogen at tea agricultural soil in Eastern Black Sea region. Journal of Ege University Faculty of Agriculture, 1993, 30, pp. 57-64.

11. Müftüoğlu, N.M.; Yüce, E.; Turna, T.; Kabaoğlu, A.; Özer, S.P.; Tanyel, G. Assessment of soil and plant properties in tea agriculture made areas. Journal of Ege University Faculty of Agriculture, 2010, 45, pp. 309-316.

12. Müftüoğlu, N.M.; Özer, S.P.; Tanyel, G.; Kabaoğlu, A. Changes occurring depend on time at some plant nutrientin eastern black sea region soils made tea agricultural. Journal of Ege University Faculty of Agriculture, 2012, 47, pp. 167-168.

13. Sarimehmet, M.; Müftüoğlu, N.M.; Yılmaz, E. Determination of plant nutrient content and physical structure in our country the tea soil, Tea Authority Headquarters. Tea Research Institute Working Paper, 1982, pp. 71-92.

14. Bilen, S.; Yıldırım S. Effects of Plant Nutrient availability on soil reaction, Journal of Atatürk University, Faculty of Agriculture, 1993, 24, pp. 156-166.

15. Kacar, B.; Przemeck, E.; Özgümüş, A.; Turan, C.; Katkat, A.V.; Kayıkçıŏlu, İ. A study on the microelement necessity of tea plants and soils in Turkey. Ankara:Tubitak, 1979, pp. $67-68$ (in Turkish). 